TITLE:

\title{
Discontinuous Dynamics of Electric Power System with DC Transmission: A Study on DAE System
}

\section{AUTHOR(S):}

Susuki, Yoshihiko; Hikihara, Takashi; Chiang, HsiaoDong

\section{CITATION:}

Susuki, Yoshihiko ...[et al]. Discontinuous Dynamics of Electric Power System with DC Transmission: A Study on DAE System. IEEE transactions on circuits and systems. I,

Regular papers 2008, 55(2): 697-707

ISSUE DATE:

2008-03

URL:

http://hdl.handle.net/2433/50530

\section{RIGHT:}

(c) Copyright 2008 IEEE - All Rights Reserved; この論文は出版社版であ りません。引用の際には出版社版をご確認ご利用ください。; This is not the published version. Please cite only the published version. 


\title{
Discontinuous Dynamics of Electric Power System with DC Transmission: A Study on DAE System
}

\author{
Yoshihiko Susuki, Member, IEEE, Takashi Hikihara, Member, IEEE, and Hsiao-Dong Chiang Fellow, IEEE,
}

\begin{abstract}
Transient stability of power systems with de transmission is an important problem for planing and operation of future power networks. A differential-algebraic equation (DAE) system is proposed for transient stability analysis of a practical ac/dc power system which includes one synchronous generator operating onto both ac and de transmissions. When transient stability analysis is performed using the DAE system, its solutions that represent dynamics of the ac/dc power system become discontinuous. This is because a constraint set, which is a set of variables satisfying algebraic equations of the DAE system, discontinuously changes at the onset of fault occurrence and clearing. We numerically and analytically examine such discontinuous solutions of the DAE system and associated transient dynamics of the ac/dc power system. The discontinuous nature of solutions shows that enhancement of transient stability via dc transmission is characterized by a dynamical system on constraint set or manifold controlled by input as installation of dc transmission.
\end{abstract}

Index Terms-power system, de transmission, transient stability, differential-algebraic equation, discontinuous solution, singular perturbation

\section{INTRODUCTION}

D C TRANSMISSION systems or dc links have been widely applied to conventional electric power systems [1], [2]. They have been traditionally utilized in areas where there is a clear financial advantage or where they are technically the only solutions. The references [3]-[5] note that dc links are nowadays adopted in much larger areas of power system operation and planning such as stabilization of power systems, high voltage (HV) transmission, and long distance transmission. The Kii channel HVDC Link in Japan [6] is a well-known modern installation of dc links. DC-based power technology also plays a key role in future systems under competitive markets to deliver electricity between different asynchronous areas [3].

The problem of estimating transient stability in electric power systems with dc transmission is of fundamental im-

Manuscript received May 9, 2006; and revised April 24, 2007 and July, 2007. This paper was recommended by..

This research is supported in part by the Ministry of Education, Culture, Sports, Sciences and Technology in Japan, The 21st Century COE Program \#14213201, Grant-in-Aid for Exploratory Research, \#16656089, 2005, and Young Research (B) \#18760216, 2006.

Y. Susuki and T. Hikihara are with Department of Electrical Engineering, Kyoto University, Katsura, Nishikyo, Kyoto, 615-8510, Japan (susuki@ dove.kuee.kyoto-u.ac.jp; hikihara@kuee.kyoto-u.ac.jp). T. Hikihara is presently also with Photonics and Electronics Science and Engineering Research Center, Kyoto University. FAX (Y.S.): +81-75-383-2243

H. -D. Chiang is with School of Electrical and Computer Engineering, Cornell University, Ithaca, NY, 14853, United States (chiang@ece.cornell.edu). portance for power system planning and operation. Transient stability is concerned with a power system's ability to reach an acceptable (steady-state) operating condition following an event disturbance [7], [8]. The stability is governed by nonlinear transient dynamics [9] of power systems. As stated above, dc links are expected to stabilize conventional ac power systems. One of their potential abilities is to eliminate operating constraints of ac power systems caused by transient stability. Another is to enhance transient stability of ac power systems using dc links [10]-[13]. Both the effects of dc links have great significance for operation and planning of future power systems. However, these mechanisms have not been fully understood from an analytical point of view. This provides a motivation to analytical studies on transient dynamics and stability of ac/dc power systems.

Transient stability of ac/dc power systems is mainly analyzed via the two different approaches. One is numerical simulation with analog or digital computers, e.g., [10], [14], [15]. The numerical approach is applicable to estimating transient stability with considering detailed behaviors of ac/dc power systems. The other is direct analysis of transient stability: energy functions approach [16]-[19] and dynamical systems methods [20]. The analytical approach has a potential to clarifying the mechanisms of transient stability of ac/dc power systems and stabilization via dc links.

As one of the analytical studies on transient stability, in this paper, discontinuous transient dynamics is examined for an electric power system with dc transmission. A differentialalgebraic equation (DAE) system is proposed in [21]-[23] for transient stability analysis of a practical ac/dc power system which includes one synchronous generator operating onto both ac and dc transmissions. When transient stability analysis is performed using the DAE system, its solutions that represent dynamics of the ac/dc power system become discontinuous. This is because a constraint set, which is a set of variables satisfying algebraic equations of the DAE system, discontinuously changes at the onset of fault occurrence and clearing. This paper focuses on such discontinuous solutions of the DAE system and associated transient dynamics of the ac/dc power system. The purpose of this paper is twofold. One is to exhibit discontinuous solutions of the DAE system. The other is to analyze transient stability of the ac/dc power system through discontinuous solutions. The analysis provides an important clue for clarifying the mechanism of transient stabilization via de link. A preliminary discussion for this paper is presented in [24] which does not have any content in Sections V and VI. 


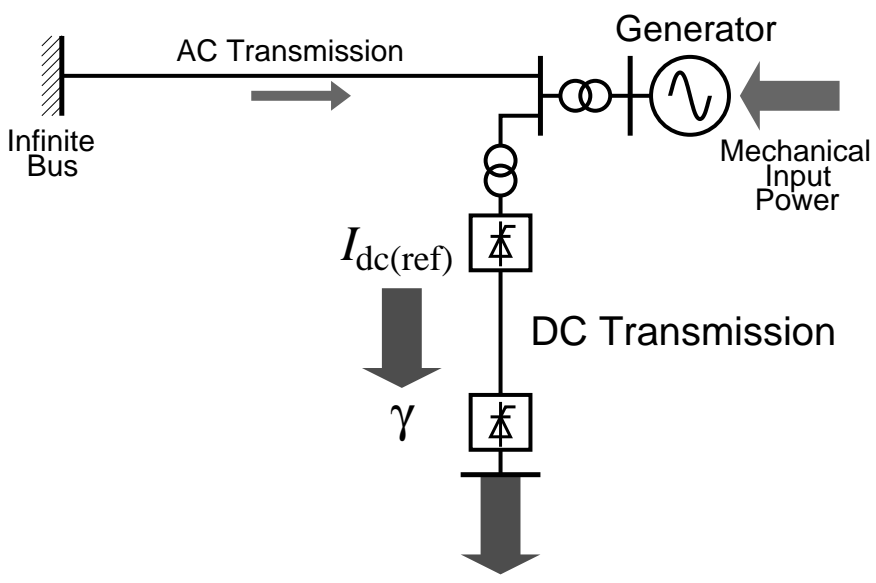

Fig. 1. Electric power system with dc transmission

Investigating transient stability of power systems based on discontinuous solutions is not a new approach. For a structure preserving model [25], the existence of discontinuous solutions has been reported. Sastry and Varaiya [26] analyze such discontinuity appearing in transient stability analysis. Chu [9] investigates detailed features of discontinuous solutions and calls them external jumps. Zho et al. [27] propose a controlling UEP (Unstable Equilibrium Point) method for transient stability analysis with considering external jumps. We apply the above results to analysis of a practical ac/dc power system.

This paper is organized as follows. Section II introduces a DAE system for transient stability analysis of an ac/dc power system and provides some remarks on the DAE system. In Sections III and IV, discontinuous solutions of the DAE system are addressed numerically and analytically. Section III exhibits several numerical results of discontinuous solutions and also shows an application limit of the DAE model for transient stability analysis. Section IV examines the discontinuous solutions using singular perturbation, thereby validating them analytically. Section V numerically investigates transient stability of the ac/dc power system through discontinuous solutions. Section VI provides several interpretations of discontinuous transient dynamics of the ac/dc power system and transient stabilization via dc link. Section VII concludes this paper with a summary and future directions.

\section{DAE SYSTEM}

The second section presents a model system of electric power systems with de transmission and a DAE system for its transient stability analysis. Some remarks of the DAE system are also arranged.

\section{A. Model system and mathematical formulation}

Figure 1 shows a model configuration of electric power systems with dc transmission. The model consists of single synchronous generator-infinite bus system and one dc link which is connected onto the bus of synchronous generator. An infinite bus is a source of voltage constant in phase, magnitude, and frequency, and is not affected by the amount of current withdrawn from it [7]. The simple configuration of Fig. 1 is based on a practical power system in Japan [6]. This paper investigates transient stability of the ac/dc power system, in other words, electro-mechanical dynamics of the synchronous generator following an accidental fault.

The following DAE system is derived in [21]-[23] as a mathematical model for transient stability analysis of the ac/dc power system in Fig. 1:

$$
\begin{aligned}
& \int \frac{T_{d 0}^{\prime}}{L_{d}-L_{d}^{\prime}} \frac{\mathrm{d} v_{q}^{\prime}}{\mathrm{d} t}=\frac{V_{0}}{L_{d}-L_{d}^{\prime}}+\frac{v_{\mathrm{r}}}{L_{d}^{\prime}} \cos \delta_{\mathrm{r}} \\
& -\frac{L_{d}}{L_{d}^{\prime}\left(L_{d}-L_{d}^{\prime}\right)} v_{q}^{\prime} \\
& \frac{\mathrm{d} \delta}{\mathrm{d} t} \quad=\omega \\
& 2 H \frac{\mathrm{d} \omega}{\mathrm{d} t} \quad=-D \omega+p_{\mathrm{m}} \\
& -\left(\frac{v_{q}^{\prime} v_{\mathrm{r}}}{L_{d}^{\prime}} \sin \delta_{\mathrm{r}}+\frac{v_{\mathrm{r}}^{2}}{2} \frac{L_{d}^{\prime}-L_{q}}{L_{d}^{\prime} L_{q}} \sin 2 \delta_{\mathrm{r}}\right), \\
& L_{\mathrm{dc}} \frac{\mathrm{d} I_{\mathrm{dc}}}{\mathrm{d} t}=-R_{\mathrm{dc}} I_{\mathrm{dc}}+K_{V}\left(v_{\mathrm{r}} \cos \alpha-V_{\mathrm{i}} \cos \gamma\right) \text {, } \\
& 0 \quad=\left(\frac{v_{q}^{\prime} v_{\mathrm{r}}}{L_{d}^{\prime}} \sin \delta_{\mathrm{r}}+\frac{v_{\mathrm{r}}^{2}}{2} \frac{L_{d}^{\prime}-L_{q}}{L_{d}^{\prime} L_{q}} \sin 2 \delta_{\mathrm{r}}\right) \\
& +\frac{v_{\mathrm{r}} V_{\infty}}{L_{\infty}} \sin \left(\delta_{\mathrm{r}}-\delta\right)-K_{I} v_{\mathrm{r}} I_{\mathrm{dc}} \cos \varphi_{\mathrm{r}}, \\
& 0=\left(\frac{v_{q}^{\prime} v_{\mathrm{r}}}{L_{d}^{\prime}} \cos \delta_{\mathrm{r}}-\frac{v_{\mathrm{r}}^{2}}{2} \frac{L_{d}^{\prime}+L_{q}}{L_{d}^{\prime} L_{q}}\right. \\
& \left.+\frac{v_{\mathrm{r}}^{2}}{2} \frac{L_{d}^{\prime}-L_{q}}{L_{d}^{\prime} L_{q}} \cos 2 \delta_{\mathrm{r}}\right) \\
& +\left\{\frac{v_{\mathrm{r}} V_{\infty}}{L_{\infty}} \cos \left(\delta_{\mathrm{r}}-\delta\right)-\frac{v_{\mathrm{r}}^{2}}{L_{\infty}}\right\} \\
& -K_{I} v_{\mathrm{r}} I_{\mathrm{dc}} \sin \varphi_{\mathrm{r}} \\
& 0 \quad=K_{I} v_{\mathrm{r}} I_{\mathrm{dc}} \cos \varphi_{\mathrm{r}} \\
& -\left(K_{V} v_{\mathrm{r}} \cos \alpha-\frac{3}{\pi} X_{\mathrm{c}} I_{\mathrm{dc}}\right) I_{\mathrm{dc}}
\end{aligned}
$$

where

$$
\alpha=G_{\alpha}\left(I_{\mathrm{dc}(\mathrm{ref})}-I_{\mathrm{dc}}\right) .
$$

The physical meaning of variables and parameters is shown in Tab. I. All variables and parameters of the DAE system (1) are in per unit except for angles which are in radians. $v_{\mathrm{r}}$ and $\delta_{\mathrm{r}}$ are defined as

$$
e_{d}=v_{\mathrm{r}} \sin \delta_{\mathrm{r}} \quad e_{q}=v_{\mathrm{r}} \cos \delta_{\mathrm{r}},
$$

where $e_{d}$ and $e_{q}$ denote $d$-axis and $q$-axis voltages of generator terminal. $v_{\mathrm{r}}$ therefore stands for terminal voltage at generator bus. It is here assumed that the value of terminal voltage is positive, that is, $v_{\mathrm{r}}>0$. The assumption is valid for the practical power system. The direct product set $X \times Y$ of variables in the DAE system (1) is defined as $X \triangleq$ $\mathbb{R} \times \mathbb{S}^{1} \times \mathbb{R} \times \mathbb{R} \ni\left(v_{q}^{\prime}, \delta, \omega, I_{\mathrm{dc}}\right)^{\mathrm{T}}$ and $Y \triangleq\left\{v_{\mathrm{r}} \mid v_{\mathrm{r}}>\right.$ 
TABLE I

PHYSICAL MEANINGS OF VARIABLES AND PARAMETERS IN THE DAE SYSTEM (1)

\begin{tabular}{ll}
\hline \hline$v_{q}^{\prime}$ & voltage behind transient reactance \\
\hline$\delta$ & rotor position with respect to synchronous reference axis \\
\hline$\omega$ & rotor speed deviation relative to system angular frequency \\
\hline$I_{\mathrm{dc}}$ & dc current: averaged value of current in dc lines \\
\hline$v_{\mathrm{r}}$ & terminal voltage at generator bus \\
\hline$\delta_{\mathrm{r}}$ & angle related to terminal voltage $v_{\mathrm{r}}$ : see eq. $(3)$ \\
\hline$\varphi_{\mathrm{r}}$ & power factor angle of rectifier \\
\hline$t$ & normalized time \\
\hline$L_{d}, L_{q}$ & $d$ - and $q$-axis synchronous reactance \\
\hline$L_{d}^{\prime}$ & $d$-axis transient reactance \\
\hline$T_{d 0}^{\prime}$ & open-circuit transient time constant \\
\hline$V_{0}$ & field excitation voltage \\
\hline$p_{\mathrm{m}}$ & mechanical input power to generator \\
\hline$H_{\mathrm{d}}$ & inertia constant \\
\hline$D$ & damping coefficient \\
\hline$V_{\infty}$ & terminal voltage at infinite bus \\
\hline$L_{\mathrm{dc}}$ & reactance of dc lines \\
\hline$R_{\mathrm{dc}}$ & resistance of dc lines \\
\hline$V_{\mathrm{i}}$ & terminal voltage at inverter bus \\
\hline$X_{\mathrm{C}}$ & coupling coefficients of ac and dc transmissions \\
\hline \hline
\end{tabular}

$0\} \times \mathbb{S}^{1} \times \mathbb{S}^{1} \ni\left(v_{\mathrm{r}}, \delta_{\mathrm{r}}, \varphi_{\mathrm{r}}\right)^{\mathrm{T}}$. The symbol $\mathrm{T}$ denotes the transpose operation of vectors.

The DAE system (1) is, needless to say, a combination of differential and algebraic equations. The first differential equation stands for dynamics of flux decay in the generator. The second and third equations show electro-mechanical dynamics of the generator, called swing equation. The fourth equation denotes dynamics of dc current which is represented by Kirchhoff's current law. The equation for dc current includes basic control setup of dc link: automatic current regulation (ACR) scheme for rectifier and automatic margin angle regulation $(\mathrm{A} \gamma \mathrm{R})$ scheme for inverter. On the other hand, the first and second algebraic equations represent active and reactive power balance in the ac power system. The last equation denotes active power relationship between the ac power system and the dc link.

Next, we rewrite the DAE system (1) via structure preserving model [28]. The following transformation reveals analytical features of transient stability of the ac/dc power system in Sections IV-VI. A variable transformation from $\left(v_{\mathrm{r}}, \delta_{\mathrm{r}}\right)$ to $\left(\theta_{\mathrm{r}}, V_{\mathrm{r}}\right)$ is introduced as

$$
\theta_{\mathrm{r}} \triangleq \delta-\delta_{\mathrm{r}}, \quad V_{\mathrm{r}} \triangleq \ln v_{\mathrm{r}}
$$

The new variable $\theta_{\mathrm{r}}$ is the phase difference between terminal voltages at generator and infinite buses system. Here, smooth functions $\mathcal{U}_{\mathrm{ac}}\left(v_{q}^{\prime}, \delta, \omega, \theta_{\mathrm{r}}, V_{\mathrm{r}}\right)$ and $\mathcal{U}_{\mathrm{dc}}\left(I_{\mathrm{dc}}\right)$ are defined as

$$
\left\{\begin{aligned}
\mathcal{U}_{\mathrm{ac}} & \triangleq-p_{\mathrm{m}} \delta \\
& -\frac{\left(L_{d}^{\prime}-L_{q}\right) \cos 2\left(\delta-\theta_{\mathrm{r}}\right)-\left(L_{d}^{\prime}+L_{q}\right)}{2 L_{d}^{\prime} L_{q}} \frac{\mathrm{e}^{2 V_{\mathrm{r}}}}{2} \\
& -\frac{v_{q}^{\prime} \mathrm{e}^{V_{\mathrm{r}}}}{L_{d}^{\prime}} \cos \left(\delta-\theta_{\mathrm{r}}\right)-\frac{\mathrm{e}^{V_{\mathrm{r}}} V_{\infty}}{L_{\infty}} \cos \theta_{\mathrm{r}} \\
& +\frac{\mathrm{e}^{2 V_{\mathrm{r}}}}{2 L_{\infty}}-\frac{V_{0}}{L_{d}-L_{d}^{\prime}} v_{q}^{\prime}+\frac{L_{d}}{L_{d}^{\prime}\left(L_{d}-L_{d}^{\prime}\right)} \frac{v_{q}^{\prime 2}}{2}, \\
\mathcal{U}_{\mathrm{dc}} & \triangleq \frac{1}{2} R_{\mathrm{dc}} I_{\mathrm{dc}}^{2} .
\end{aligned}\right.
$$

The original DAE system (1) is then re-formalized as follows:

$$
\left\{\begin{aligned}
\frac{T_{d 0}^{\prime}}{L_{d}-L_{d}^{\prime}} \frac{\mathrm{d} v_{q}^{\prime}}{\mathrm{d} t} & =-\frac{\partial \mathcal{U}_{\mathrm{ac}}}{\partial v_{q}^{\prime}}, \\
\frac{\mathrm{d} \delta}{\mathrm{d} t} & =\omega \\
2 H \frac{\mathrm{d} \omega}{\mathrm{d} t} & =-D \omega-\frac{\partial \mathcal{U}_{\mathrm{ac}}}{\partial \delta}, \\
L_{\mathrm{dc}} \frac{\mathrm{d} I_{\mathrm{dc}}}{\mathrm{d} t} & =-\frac{\partial \mathcal{U}_{\mathrm{dc}}}{\partial I_{\mathrm{dc}}}+K_{V}\left(\mathrm{e}^{V_{\mathrm{r}}} \cos \alpha-V_{\mathrm{i}} \cos \gamma\right), \\
0 & =-\frac{\partial \mathcal{U}_{\mathrm{ac}}}{\partial \theta_{\mathrm{r}}}-K_{I} \mathrm{e}^{V_{\mathrm{r}}} I_{\mathrm{dc}} \cos \varphi_{\mathrm{r}}, \\
0 & =-\frac{\partial \mathcal{U}_{\mathrm{ac}}}{\partial V_{\mathrm{r}}}-K_{I} \mathrm{e}^{V_{\mathrm{r}}} I_{\mathrm{dc}} \sin \varphi_{\mathrm{r}}, \\
& =K_{I} \mathrm{e}^{V_{\mathrm{r}}} I_{\mathrm{dc}} \cos \varphi_{\mathrm{r}} \\
& -\left(K_{V} \mathrm{e}^{V_{\mathrm{r}}} \cos \alpha-\frac{3}{\pi} X_{\mathrm{c}} I_{\mathrm{dc}}\right) I_{\mathrm{dc}} .
\end{aligned}\right.
$$

The simple description of transformed DAE system (6) is often used as follows:

$$
\left\{\begin{array}{c}
\mathrm{M} \frac{\mathrm{d} \boldsymbol{x}}{\mathrm{d} t}=\boldsymbol{f}(\boldsymbol{x}, \boldsymbol{y}) \\
\mathbf{0}=\boldsymbol{g}(\boldsymbol{x}, \boldsymbol{y})
\end{array}\right.
$$

where $\boldsymbol{x} \triangleq\left(v_{q}^{\prime}, \delta, \omega, I_{\mathrm{dc}}\right)^{\mathrm{T}} \in X=\mathbb{R} \times \mathbb{S}^{1} \times \mathbb{R} \times \mathbb{R}, \boldsymbol{y} \triangleq$ $\left(\theta_{\mathrm{r}}, V_{\mathrm{r}}, \varphi_{\mathrm{r}}\right)^{\mathrm{T}} \in \mathbb{S}^{1} \times \mathbb{R} \times \mathbb{S}^{1}$, and $\boldsymbol{f}$ stands for right-hand sides of differential equations in the DAE system (6) and $g$ righthand sides of algebraic equations. $M$ is the positive-definite diagonal matrix:

$$
\mathrm{M} \triangleq \operatorname{diag}\left(\frac{T_{d 0}^{\prime}}{L_{d}-L_{d}^{\prime}}, 1,2 H, L_{\mathrm{dc}}\right)
$$

\section{B. Remarks}

The mathematical formulation of transient stability in ac/dc power systems via DAEs is not new. Various DAEs have been used for stability analysis of power systems, e.g., [25], [26], [28]-[35]. The previous works present some basic characteristics of DAEs, with which the DAE system (1) can be examined analytically. Several researchers have also modeled the dynamics of ac/dc power systems via DAEs. Padiyar et al. [1], [19] derive a structure preserving model for transient stability analysis of ac/dc power systems. Cañizares et al. [36] 
also use a DAE-based voltage stability model for ac/dc power systems.

The model used in this paper is a simplified one, because only constant dc current control and margin angle one are adopted, when in reality there are also firing and extinction angle controls and VDCOL scheme [1], [2]. It is now necessary to consider whether the DAE system (1) is applicable to analysis of the ac/dc power system. Peterson et al. [14] note that there are the two main different points of the analysis of ac/dc power systems from those of ordinary ac power systems:

1) Transients on the dc line are of a much lower frequency than those on the ac line because of the large inductances connected in the dc line. Therefore, they should be considered when the transient stability of the composite system is studied.

2) The speed of response of the dc control equipment can be expected to be faster by orders of magnitude, when compared with the power-swing. (The possibility of inverter commutation failure should also be taken into account.)

Through the above two points, we now consider whether the DAE-based model is tractable for the present analysis. The first point is achieved by considering dynamics of dc current. The DAE system (1) includes their mathematical model. Here, transients on ac lines are of a much faster frequency than those of electro-mechanical swing of the generator. Dynamics of the ac transmission can be therefore eliminated. The second point is also implemented by considering control setup of dc link. The equation (2) shows a simple description of ACR scheme. There is also no need to consider a possibility of inverter commutation failure in the ac/dc power system, because dynamics of ac power systems on the inverter side is not modeled in Fig. 1. Here, time frame of transient stability is from around a second to several seconds [7]. Interrupted voltage and current by ac/dc converters can be therefore expressed with these time-averaged values, which are used in the DAE system (1). Transient dynamics of the ac/dc power system can be hence modeled using the DAE system (1).

\section{NUMERICAL SIMULATIONS OF DISCONTINUOUS SOLUTIONS}

This section exhibits several discontinuous solutions of the DAE system (1). Two fault conditions in the ac power system are fixed for numerical simulations. The concepts of discontinuous solutions are also reviewed.

\section{A. Fault conditions and external jumps}

Two fault conditions for numerical simulations are as follows. One is a three-phase fault in the ac transmission, and the generator as a result operates onto only the dc link during the fault duration. The other is a three-phase fault near the infinite bus, and thereby the infinite bus voltage is fixed at zero during the fault duration. Suppose that all variables of the DAE system (1) are at a known stable equilibrium point (EP) at time $t=0^{-}$. This implies that the ac/dc power system exists on a steady state at time $t=0^{-}$. Also suppose that a large fault occurs at time $t=0$ and that the fault is cleared at
TABLE II

PARAMETER SETTING IN THE DAE SYSTEM (1)

\begin{tabular}{llllll}
\hline \hline$L_{d}$ & 1.79 & $L_{q}$ & 1.77 & $L_{d}^{\prime}$ & 0.34 \\
\hline$T_{d 0}^{\prime} /\left(120 \pi \mathrm{s}^{-1}\right)$ & $6.3 \mathrm{~s}$ & $V_{0}$ & 1.7 & $p_{\mathrm{m}}$ & 0.5 \\
\hline$H /\left(120 \pi \mathrm{s}^{-1}\right)$ & $0.89 \mathrm{~s}$ & $D$ & 0.05 & $L_{\infty}$ & 0.883 \\
\hline$V_{\infty}$ & 1.0 & $L_{\mathrm{dc}}$ & 4.2 & $R_{\mathrm{dc}}$ & 0.014 \\
\hline$V_{\mathrm{i}}$ & 1.0 & $K_{V}$ & 1.19 & $K_{I}$ & 1.19 \\
\hline$X_{\mathrm{c}}$ & 0.12 & $G_{\alpha}$ & 30.0 & $I_{\mathrm{dc}(\mathrm{ref})}$ & 1.0 \\
\hline$\gamma$ & $23.0 \mathrm{deg}$ & & & \\
\hline \hline
\end{tabular}

time $t=t_{\mathrm{cl}}(>0)$ by system operation such as protective relay. The fault duration is confined to the time interval $\left[0^{+}, t_{\mathrm{cl}}^{-}\right]$. It is also assumed for simplicity that the pre-fault and postfault DAE systems are consistent. Thus, the above two fault conditions can be formulated during the time interval $\left[0^{+}, t_{\mathrm{cl}}^{-}\right]$ using the ac line reactance $L_{\infty}$ and the infinite bus voltage $V_{\infty}$ as follows:

$$
\left\{\begin{array}{l}
\frac{1}{L_{\infty}}=0: \text { case- } 1, \\
V_{\infty}=0: \text { case- } 2 .
\end{array}\right.
$$

Two constraint sets are apparently different between the prefault (or post-fault) and fault-on DAE systems. The difference is the origin of discontinuous solutions in the DAE system (1) at time $t=0$ and $t_{\mathrm{cl}}$. They are called external jumps [9] and have been discussed for power system models [9], [26], [27]. The external jumps are qualitatively different from jump behavior caused by singularity [37], [38]. The previous works [9], [26] characterize the discontinuous solutions via boundary layer (BL) systems. The following sections use some of the previous results to validate numerical external jumps of the DAE system (1).

Note that actual power systems do not hold such discontinuous states and that they therefore originate from modeling over-abstraction. However, it should be emphasized that the analysis of ideal discontinuous solutions is of great significance due to the two facts. One is that in actual power systems rapid change of power flows by protective relay operations is often observed. Such rapid dynamics can be approximately modeled with the discontinuous solutions. The other is related to computational aspects of power system analysis. Abstraction is an inevitable task for computer-aided analysis of massively complex power systems. As stated above, general DAEs provide a fruitful mathematical model for power system transient stability analysis. Understanding the discontinuous solutions is thus important from both the phenomenological and engineering points of view.

\section{B. Numerical simulations}

Numerical simulations are performed for the above two fault conditions. Tab. II shows the parameter setting in the DAE system (1). $L_{\infty}$ and $V_{\infty}$ in Tab. II are adopted except the fault duration $\left[0^{+}, t_{\mathrm{cl}}^{-}\right]$. The parameters are obtained for a practical power system [6]. This paper adopts the 3rd-stage Radau-IIA implicit Runge-Kutta method [39] to integrate the DAE system numerically. 


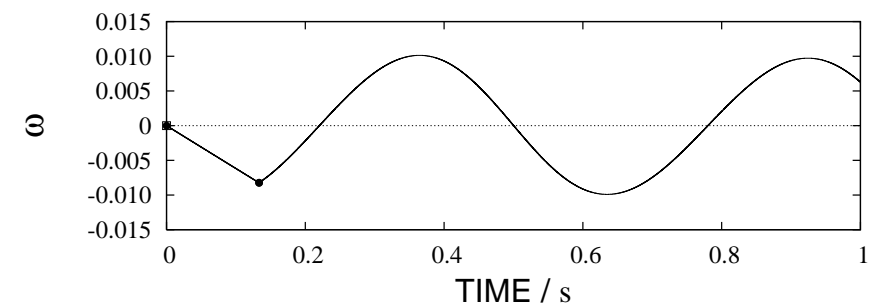

(a) Rotor speed deviation $\omega$

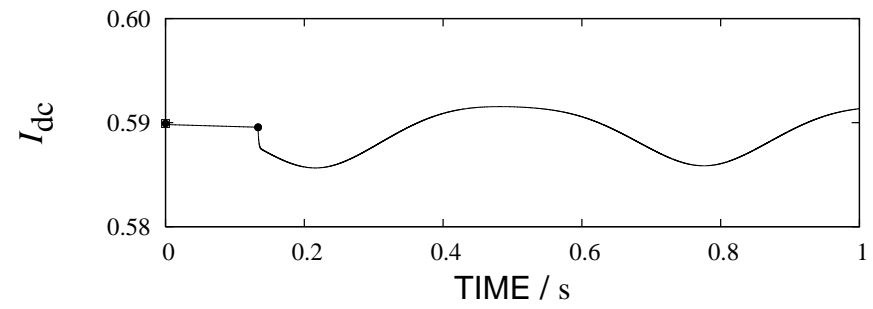

(b) DC current $I_{\mathrm{dc}}$

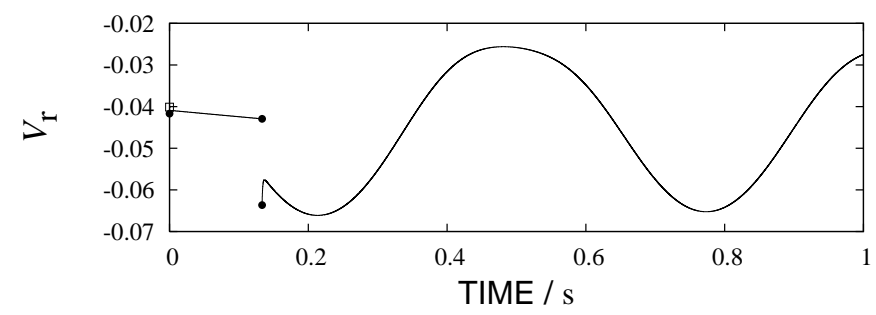

(c) $V_{\mathrm{r}}=\ln v_{\mathrm{r}}$ for terminal voltage $v_{\mathrm{r}}$

Fig. 2. Discontinuous solution of the DAE system (1) with case-1 fault condition. The fault-clearing time $t_{\mathrm{cl}} /\left(120 \pi \mathrm{s}^{-1}\right)$ is fixed at $8 /(60 \mathrm{~Hz})$. The solution converges to a post-fault stable equilibrium point (EP) as time passes.

Figure 2 shows the transient behavior of $\omega, I_{\mathrm{dc}}$, and $V_{\mathrm{r}}$ with case- 1 fault condition. The fault clearing time is 8 cycle of a $60 \mathrm{~Hz}$ sine wave: $t_{\mathrm{cl}} /\left(120 \pi \mathrm{s}^{-1}\right)=8 /(60 \mathrm{~Hz})$. The solution converges to a post-fault stable EP as time passes. In Fig. 2, $\omega$ and $I_{\mathrm{dc}}$ in the variable $\boldsymbol{x}$ of differential equations are continuous. On the other hand, $V_{\mathrm{r}}$ in the variable $\boldsymbol{y}$ of algebraic equations is discontinuous at $t /\left(120 \pi \mathrm{s}^{-1}\right)=0 \mathrm{~s}$ and $8 /(60 \mathrm{~Hz})$. The distinctive feature of continuity is clarified via singular perturbation in Section IV.

Figure 2 also describes the active and reactive power swing of generator and infinite bus outputs, and dc input. The active and reactive power also includes the discontinuous points at $t /\left(120 \pi \mathrm{s}^{-1}\right)=0 \mathrm{~s}$ and $8 /(60 \mathrm{~Hz})$. During the fault duration, the active power output from infinite bus is zero. The active power output from generator and input to dc link are therefore consistent. Since the active power output from generator during the fault duration is greater than that at the pre-fault time, the generator is decelerated in Fig. 2(a). After the fault is cleared at $t=t_{\mathrm{cl}}$, both the active power output from generator and infinite bus shows oscillatory motions and converges to constant values at the stable EP. Here it should be noted that rapid transients of active and reactive power are reported in [14] with numerical simulations of detailed model of an ac and dc parallel transmission system. These rapid transients are well approximated by the discontinuous solutions presented here.

Figure 3 shows the transient behavior with case- 2 fault

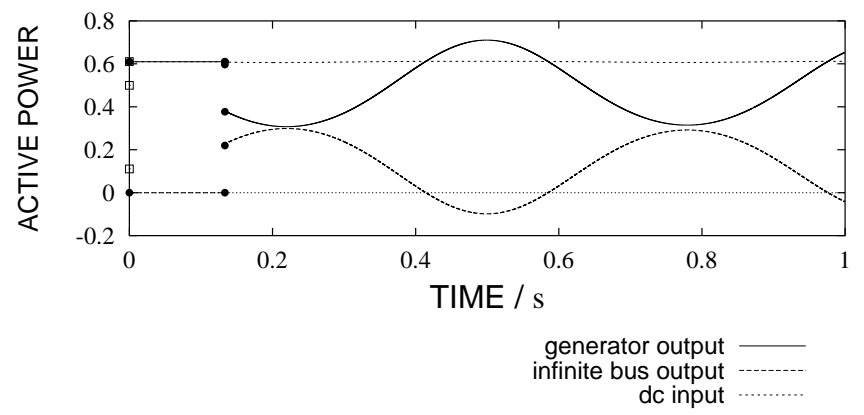

(d) Active power

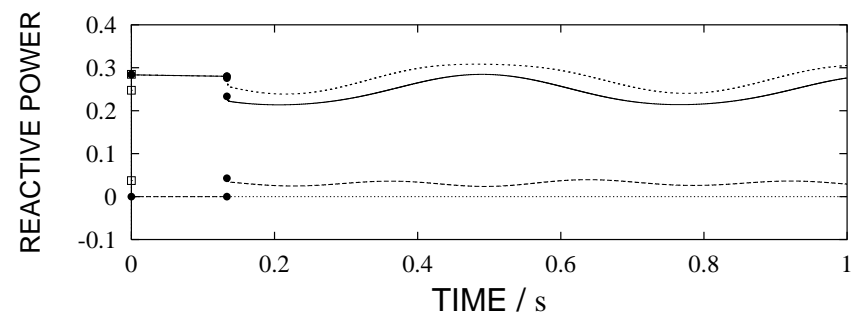

(e) Reactive power

Fig. 2. (continued)

condition. The solution converges to the singular surface [40] of fault-on DAE system in a finite time. For the system (7), the singular surface $S$ is defined as

$$
\begin{aligned}
S \triangleq & \{(\boldsymbol{x}, \boldsymbol{y}) \in X \times Y \mid \boldsymbol{g}(\boldsymbol{x}, \boldsymbol{y})=\mathbf{0}, \\
& \left.\operatorname{det}\left(\mathrm{D}_{y} \boldsymbol{g}\right)(\boldsymbol{x}, \boldsymbol{y})=0\right\} .
\end{aligned}
$$

The solution which reaches the singular surface becomes possibly discontinuous [37], [38]. The discontinuity here is qualitatively different from external jumps [9] and implies the loss of causality of the DAE system as a power system model [30], [31]. On the singular surface we cannot predict transient stability of the ac/dc power system by the DAE system (1). The transient behavior in Fig. 3 therefore suggests that the present DAE system (1) is not relevant to clarifying the transient stability with respect to case-2 fault condition. This shows an application limit of the DAE system (1) for transient stability analysis.

Note that the simulations above are some examples of discontinuous solutions in the DAE system (1). The behavior of discontinuous solutions qualitatively changes depending on fault conditions which include initial states and parameters. The following sections discuss some aspects of global nature of the discontinuous solutions with application to validation of numerical solutions and analysis of transient stabilization via dc link.

\section{Analytical VAlidation of Discontinuous SOLUTIONS}

The preceding section numerically showed several discontinuous solutions of the DAE system (1). This section validates the numerical solution with case- 1 fault condition from an analytical point of view. The validation is performed using singular perturbation technique and BL formulation. 


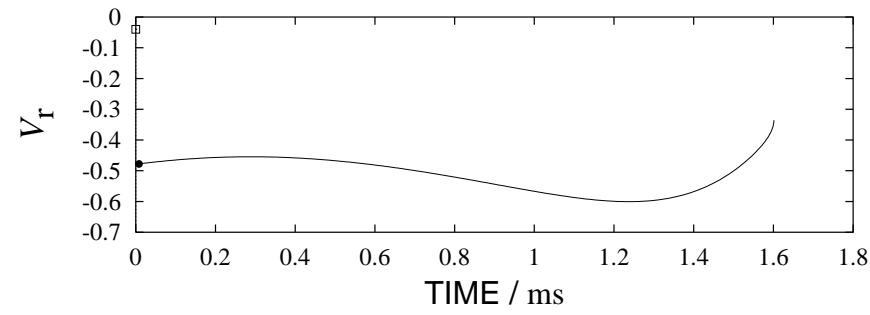

(a) $V_{\mathrm{r}}=\ln v_{\mathrm{r}}$ for terminal voltage $v_{\mathrm{r}}$

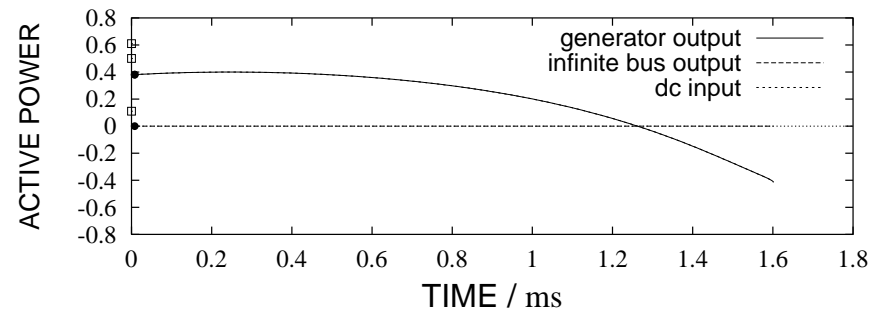

(b) Active power

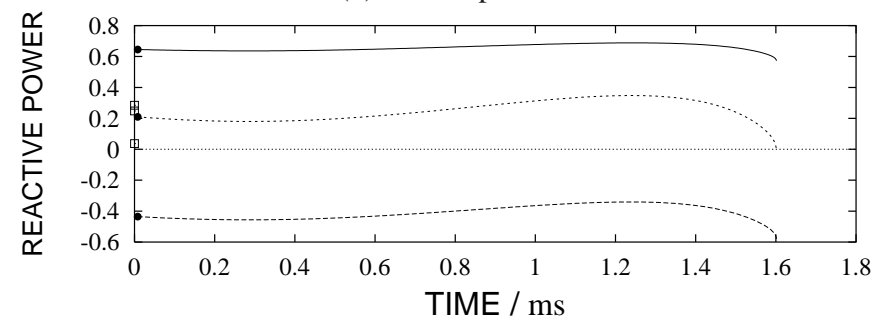

(c) Reactive power

Fig. 3. Discontinuous solution of the DAE system (1) with case-2 fault condition. The solution reaches the singular surface of fault-on DAE system in a finite time.

\section{A. Singular perturbation approach}

The discontinuous solution in Fig. 2 is considered using singular perturbation. The corresponding singularly perturbed (SP) system to the DAE system (7) with a small positive parameter $\varepsilon$ is introduced:

$$
\left\{\begin{array}{l}
\mathrm{M} \frac{\mathrm{d} \boldsymbol{x}}{\mathrm{d} t}=\boldsymbol{f}(\boldsymbol{x}, \boldsymbol{y}) \\
\varepsilon \frac{\mathrm{d} \boldsymbol{y}}{\mathrm{d} t}=\boldsymbol{g}(\boldsymbol{x}, \boldsymbol{y}) .
\end{array}\right.
$$

Dynamics of the SP system (11) has the similarity to those of the transformed DAE system (7) in some conditions and of the original DAE system (1) with additional assumptions. This important property is well known as Tihkonov's theorem [41]. Fig. 4 shows the projected trajectories of the DAE and corresponding SP systems onto $\theta_{\mathrm{r}}-V_{\mathrm{r}}$ plane. The perturbation parameter $\varepsilon$ is fixed at 0.5 . Note that trajectories of the SP system at $\varepsilon=0.01$ and 0.1 show the same behavior as that at $\varepsilon=0.5$. The solid line is for the DAE system (1): The transformations $\theta_{\mathrm{r}}=\delta-\delta_{\mathrm{r}}$ and $V_{\mathrm{r}}=\ln v_{\mathrm{r}}$ are used. The broken line is for the SP system (11) which initial condition is identical to that for the DAE system (1). Fig. 4 implies that the solution of the SP system (11) traces the discontinuous solution of the DAE system (1). The SP system (11) thus provides an overall approximation of the discontinuous solution in Fig. 2.

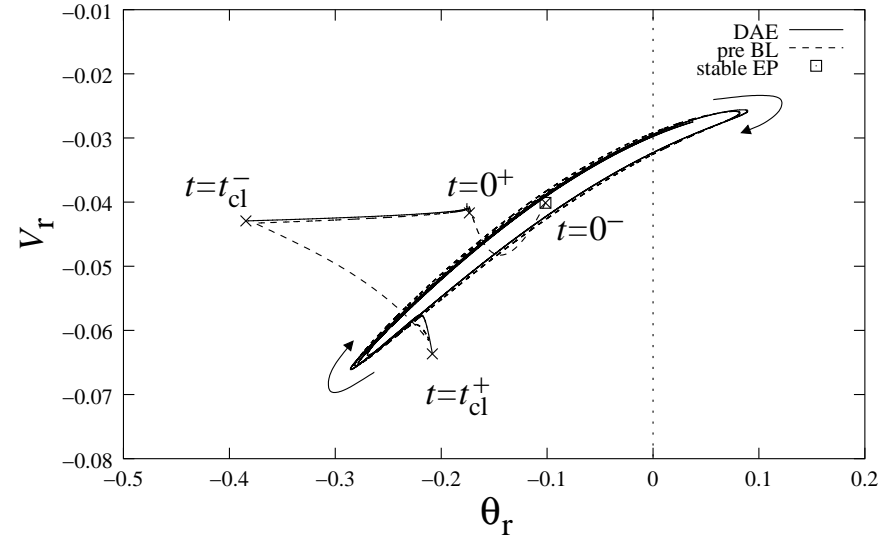

Fig. 4. Projected trajectories of the DAE and SP systems with case-1 fault condition onto $\theta_{\mathrm{r}}-V_{\mathrm{r}}$ plane. The perturbation parameter $\varepsilon$ is set at 0.5 . The solid line denotes the trajectory of the DAE system (1) shown in Fig. 2, for which the transformations $\theta_{\mathrm{r}}=\delta-\delta_{\mathrm{r}}$ and $V_{\mathrm{r}}=\ln v_{\mathrm{r}}$ are used. The broken line shows the trajectory of the SP system (11).

\section{B. Boundary layer approach}

Next the external jumps for case-1 fault condition are analytically validated. To confirm the projected discontinuous solution in Fig. 4, the following two-dimensional BL system is adopted via the scaling transformation $s=t / \varepsilon$ and under additional assumptions $v_{\mathrm{r}}>0, I_{\mathrm{dc}} \neq 0, \sin \varphi_{\mathrm{r}}>0$, and $K_{I}>0$ :

$$
\left\{\begin{aligned}
& \frac{\mathrm{d} \theta_{\mathrm{r}}}{\mathrm{d} s}=-\frac{\partial \mathcal{U}_{\mathrm{ac}}}{\partial \theta_{\mathrm{r}}}\left(v_{q}^{\prime}, \delta, \theta_{\mathrm{r}}, V_{\mathrm{r}}\right) \\
&-\left(K_{V} \mathrm{e}^{V_{\mathrm{r}}} \cos \alpha-\frac{3}{\pi} X_{\mathrm{c}} I_{\mathrm{dc}}\right) I_{\mathrm{dc}} \\
& \frac{\mathrm{d} V_{\mathrm{r}}}{\mathrm{d} s}=-\frac{\partial \mathcal{U}_{\mathrm{ac}}}{\partial V_{\mathrm{r}}}\left(v_{q}^{\prime}, \delta, \theta_{\mathrm{r}}, V_{\mathrm{r}}\right) \\
&-\sqrt{K_{I}^{2} \mathrm{e}^{2 V_{\mathrm{r}}}-\left(K_{V} \mathrm{e}^{V_{\mathrm{r}}} \cos \alpha-\frac{3}{\pi} X_{\mathrm{c}} I_{\mathrm{dc}}\right)^{2}} \cdot I_{\mathrm{dc}} .
\end{aligned}\right.
$$

The derivation of the BL system (12) is given in Appendix. The variables $v_{q}^{\prime}, \delta$, and $I_{\mathrm{dc}}$ are assumed constant when the variables $\theta_{\mathrm{r}}$ and $V_{\mathrm{r}}$ change. The BL system (12) is regarded as a dynamical system that represents dynamics of the variables $\theta_{\mathrm{r}}$ and $V_{\mathrm{r}}$.

A remark on characterization of external jumps is now introduced. It is stated from [9], [26] that if the DAE system (1) admits of an external jump at $t=t_{*}$, then the trajectory of the BL system (12) with the initial point $\left(\theta_{\mathrm{r}}\left(t_{*}^{-}\right), V_{\mathrm{r}}\left(t_{*}^{-}\right)\right)$converges to the point $\left(\theta_{\mathrm{r}}\left(t_{*}^{+}\right), V_{\mathrm{r}}\left(t_{*}^{+}\right)\right)$as time passes, satisfying $\boldsymbol{x}\left(t_{*}^{-}\right)=\boldsymbol{x}\left(t_{*}^{+}\right)$. This implies that the point $\left(\theta_{\mathrm{r}}\left(t_{*}^{-}\right), V_{\mathrm{r}}\left(t_{*}^{-}\right)\right)$ is on a stable manifold of the EP $\left(\theta_{\mathrm{r}}\left(t_{*}^{+}\right), V_{\mathrm{r}}\left(t_{*}^{+}\right)\right)$in the BL system (12). It also suggests that global phase structures of the BL system play an important role in examining the detailed features of external jumps. In the following, the points $\left(\theta_{\mathrm{r}}\left(t_{*}^{-}\right), V_{\mathrm{r}}\left(t_{*}^{-}\right)\right)$and $\left(\theta_{\mathrm{r}}\left(t_{*}^{+}\right), V_{\mathrm{r}}\left(t_{*}^{+}\right)\right)$are called the starting and exit points of external jumps at $t=t^{*}$.

The numerical simulation in Fig. 2 is now reconsidered via the above characterization. The coincident property of the variable $\boldsymbol{x}$ holds in Figs. 2(a) and (b) at $t=0$ and $t_{\mathrm{cl}}$. Fig. 5 


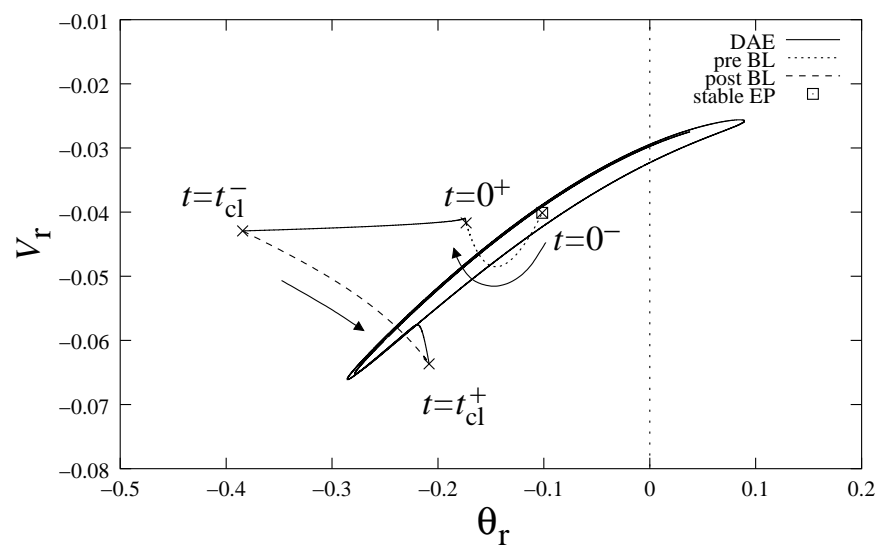

Fig. 5. Projected trajectory of the DAE system, and trajectories of the pre- and post-BL systems with case-1 fault condition. The solid line denotes the trajectory of the DAE system (1) shown in Fig. 2, for which the transformations $\theta_{\mathrm{r}}=\delta-\delta_{\mathrm{r}}$ and $V_{\mathrm{r}}=\ln v_{\mathrm{r}}$ are used. The dotted and broken lines show the trajectories of the BL systems (12) at $t=0$ and $t_{\mathrm{cl}}$.

describes the trajectories of the pre-BL and post-BL systems, and the projected trajectory of the DAE system (1), for which the transformations $\theta_{\mathrm{r}}=\delta-\delta_{\mathrm{r}}$ and $V_{\mathrm{r}}=\ln v_{\mathrm{r}}$ are used. The trajectories of the BL systems converge to EPs of the BL systems. The EPs coincide with the exit points of external jumps at $t=0$ and $t_{\mathrm{cl}}$. The analytical characterization hence validates the numerical discontinuous solution including the external jumps.

Note that the global aspect of characterization is not fully used in the above validation. Fig. 5 numerically validates at $t=0$ and $t_{\mathrm{cl}}$ that one trajectory of each BL system exists on a stable manifold of each EP. There is no discussion of global structures of the BL system (12). The global structures are investigated in Section V. The next section shows that all trajectories of the BL system (12) at $t=t_{\mathrm{cl}}$ converge to a common stable EP.

\section{TRANSIENT STABILITY ANALYSIS BASED ON DISCONTINUOUS SOLUTIONS}

This section performs transient stability analysis of the ac/dc power system based on discontinuous solutions. As stated above, transient stability is concerned with a power system's ability to reach an acceptable operating condition following an event disturbance. The previous sections investigated several discontinuous solutions and provided some analytical methods for validating them. It is therefore and now possible to examine transient stability of the ac/dc power system through discontinuous solutions. This section investigates the effects of fault clearing time and dc current control on transient dynamics and stability of the ac/dc power system.

\section{A. Effect of fault clearing time}

The effect of fault clearing time $t_{\mathrm{cl}}$ is considered for case1 fault condition. Fig. 6 shows transient behavior of the DAE system (1) at 9 cycle and 10 cycle of a $60 \mathrm{~Hz}$ sine wave: $t_{\mathrm{cl}} /\left(120 \pi \mathrm{s}^{-1}\right)=9 /(60 \mathrm{~Hz})$ and $10 /(60 \mathrm{~Hz})$. The setting of numerical simulations is identical to that in Fig. 2.

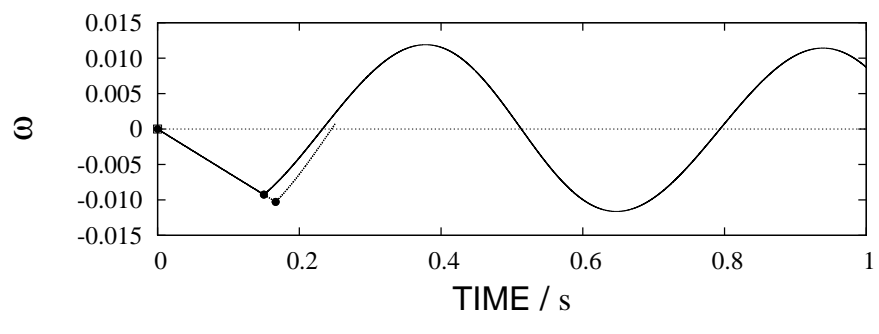

$9 /(60 \mathrm{~Hz})$ $10 /(60 \mathrm{~Hz})$

(a) Rotor speed deviation $\omega$

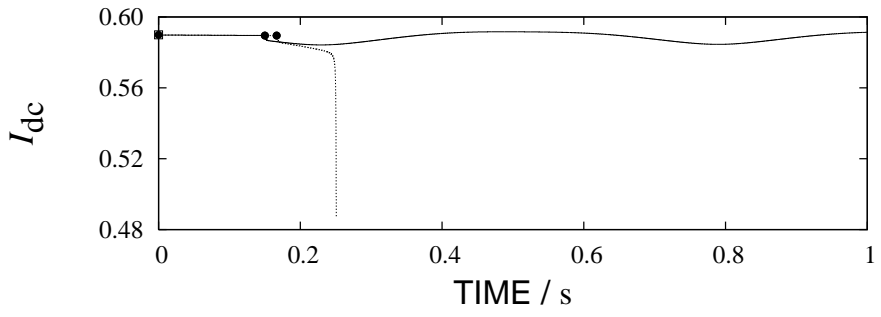

(b) DC current $I_{\mathrm{dc}}$

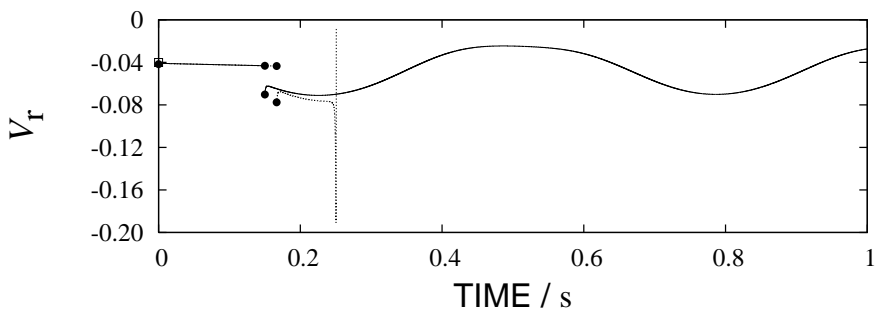

(c) $V_{\mathrm{r}}=\ln v_{\mathrm{r}}$ for terminal voltage $v_{\mathrm{r}}$

Fig. 6. Discontinuous solutions of the DAE system (1) under $t_{\mathrm{cl}} /\left(120 \pi \mathrm{s}^{-1}\right)=9 /(60 \mathrm{~Hz})$ and $10 /(60 \mathrm{~Hz})$ with case-1 fault condition. The discontinuous solution with $t_{\mathrm{cl}} /\left(120 \pi \mathrm{s}^{-1}\right)=9 /(60 \mathrm{~Hz})$ converges to a stable equilibrium point as time passes. The discontinuous solution with $t_{\mathrm{cl}} /\left(120 \pi \mathrm{s}^{-1}\right)=10 /(60 \mathrm{~Hz})$ reaches the singular surface of the post-fault DAE system in a finite time.

The discontinuous solution with $t_{\mathrm{cl}} /\left(120 \pi \mathrm{s}^{-1}\right)=9 /(60 \mathrm{~Hz})$ converges to a stable EP. This is qualitatively identical to the discontinuous solution with $t_{\mathrm{cl}} /\left(120 \pi \mathrm{s}^{-1}\right)=8 /(60 \mathrm{~Hz})$ in Fig. 2. On the other hand, the discontinuous solution with $t_{\mathrm{cl}} /\left(120 \pi \mathrm{s}^{-1}\right)=10 /(60 \mathrm{~Hz})$ reaches the singular surface $S$ of post-fault DAE system in a finite time. This implies that by the DAE system (1) we cannot predict transient stability of the ac/dc power system after the fault clearing, and that the ac/dc power system has a possibility of reaching undesirable operations due to the decrease of $\mathrm{dc}$ current and system voltage. Note in [42] that the qualitative difference between the discontinuous solutions originates from stability boundaries of the DAE system (1).

\section{B. Effect of dc current control}

Next, the effect of dc current control is addressed. The present investigation is performed for case-1 fault condition. Fig. 7 shows transient behavior of the DAE system (1) under the set-point value $I_{\mathrm{dc}(\mathrm{ref})}=1.000,0.885$, and 0.750 . The behavior is obtained by adopting a stable EP of the pre-fault DAE system as initial condition. The same parameter setting is also used as in Fig. 2. The solutions converge to stable EPs. That is, the generator settles down an acceptable operating 


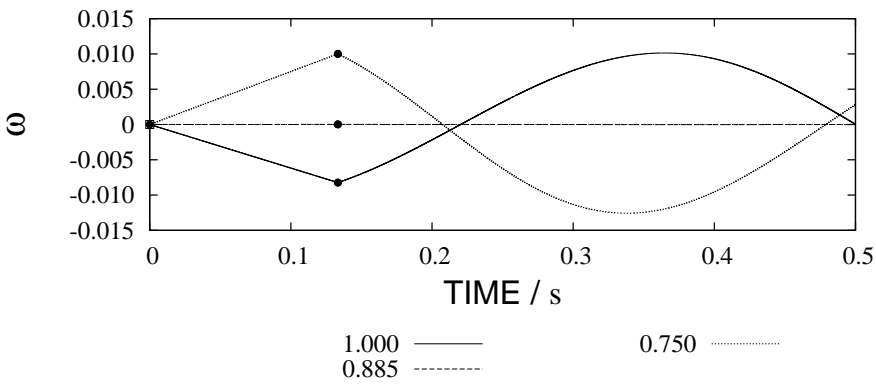

(a) Rotor speed deviation $\omega$

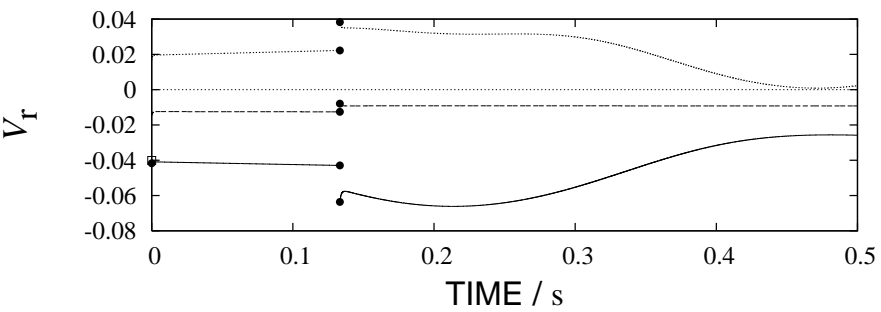

(b) $V_{\mathrm{r}}=\ln v_{\mathrm{r}}$ for terminal voltage $v_{\mathrm{r}}$

Fig. 7. Discontinuous solutions of the DAE system (1) under $I_{\mathrm{dc}(\mathrm{ref})}=$ $1.000,0.885$, and 0.750 with respect to case- 1 fault condition. The faultclearing time $t_{\mathrm{cl}} /\left(120 \pi \mathrm{s}^{-1}\right)$ is fixed at $8 /(60 \mathrm{~Hz})$. The solutions converge to stable EPs of the post-fault DAE system (1) as time passes. The figure shows accelerated state of the generator, almost steady state, and decelerated state, for the decrease of $I_{\mathrm{dc}(\mathrm{ref})}$.

condition for case-1 fault condition. The transient behavior in Fig. 2 shows accelerated state of the generator, almost steady state, and decelerated state, for the decrease of $I_{\mathrm{dc}(\mathrm{ref})}$. The dc current control hence affects transient dynamics of the overall power system.

Section IV mentioned that phase portraits of the BL system (12) characterized the detailed features of external jumps. Now the relationship between the effect of dc current control and phase portraits of the post-fault BL system (12) is considered. Fig. 8 shows phase portraits of the post-fault BL system (12) under $I_{\mathrm{dc}(\mathrm{ref})}=1.000,0.885$, and 0.750 with case-1 fault condition. Every phase portrait has one EP which corresponds to an exit point of external jump at $t_{\mathrm{cl}} /\left(120 \pi \mathrm{s}^{-1}\right)=8 /(60 \mathrm{~Hz})$. All trajectories in Fig. 8 converge to the EPs as time passes. Every broken line shows the important trajectory which connects the starting and exit points of external jumps. In Fig. 8(b) the starting and exit points are almost same, and the corresponding transient behavior in Fig. 7 does not therefore show any oscillatory motion after the fault clearing. The phase portraits hence show the effect of dc current control to external jumps. This provides an analytical clue to considering transient stabilization via dc link in Section VI.

\section{DISCUSSION}

Sections III-V showed several numerical and analytical results on discontinuous solutions in the DAE system (1). Through the discontinuous solutions, we offer mathematical and physical explanations of transient dynamics and stability of the ac/dc power system.

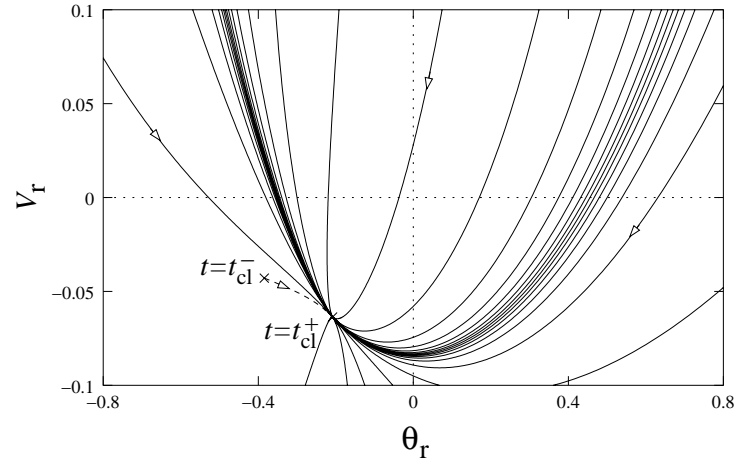

(a) $I_{\mathrm{dc}(\mathrm{ref})}=1.000$

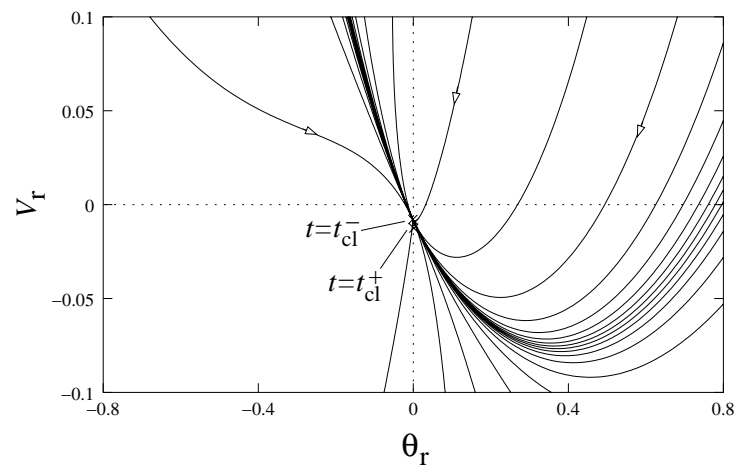

(b) $I_{\mathrm{dc}(\mathrm{ref})}=0.885$

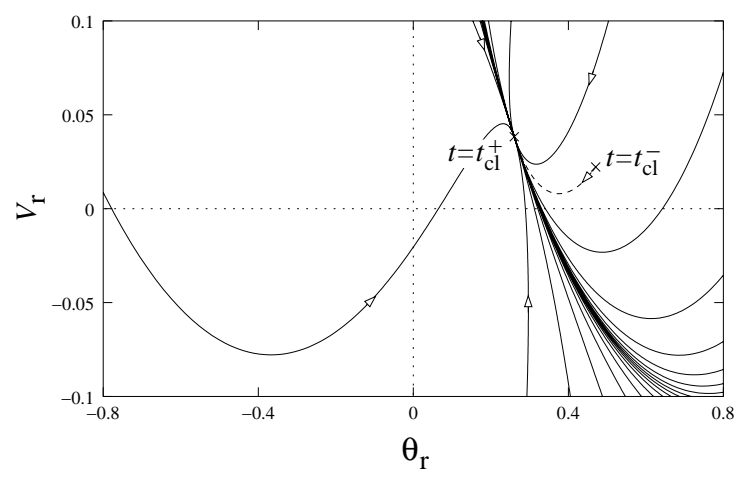

(c) $I_{\mathrm{dc}(\mathrm{ref})}=0.750$

Fig. 8. Phase portraits of the post-BL system (12) under $I_{\mathrm{dc}(\mathrm{ref})}=1.000$, 0.885 , and 0.750 with respect to case- 1 fault condition. The fault clearing time $t_{\mathrm{cl}} /\left(120 \pi \mathrm{s}^{-1}\right)$ is fixed at $8 /(60 \mathrm{~Hz})$. Every broken line shows the important trajectory which connects the starting and exit points of external jumps. All the trajectories in the figure converge to the EPs of the post-fault BL system as time passes.

\section{A. Analytical description of installation of dc link}

This paper uses a DAE-based model on transient dynamics of the ac/dc power system. The used model offers an analytical viewpoint about the installation of dc link into ac power system. Both the original DAE system (1) and the transformed one (6) imply that dynamics of the ac power system and the dc link interacts each other through active and reactive power relations. Here, without the interaction, in other words, $K_{V}=K_{I}=0$, the transformed DAE system (6) implies that dynamics of the ac power system is represented by a gradient-like system. The function $\mathcal{U}_{\mathrm{ac}}\left(v_{q}^{\prime}, \delta, \omega, \theta_{\mathrm{r}}, V_{\mathrm{r}}\right)$ 
becomes a candidate of energy function [28], [40] which leads to characterization of stability boundaries of the ac power system. Hence, from the transformed DAE system (6), the installation of dc link into ac power system is mathematically represented by a perturbation to the gradient-like system. This analytical viewpoint is held for general ac/dc composite power systems, because their dynamics can be also represented by DAE systems with structure preserving model [28].

\section{B. Mechanism of discontinuous solutions}

Section III gave several numerical results on discontinuous solutions. The origin of discontinuous dynamics is physically conservation law of power and is mathematically a set of algebraic equations. The DAE system (1) contains active and reactive power relations which are described by the algebraic equations. The power relations stem from the conservation law of active and reactive power at the connecting point of ac power system and dc link. At the onset of fault occurrence, the conservation law of power is held; on the other hand, the network topology of ac/dc power system instantaneously changes. Both these properties are compatible if the algebraic equations instantaneously change at the onset of fault occurrence. This is why the discontinuity of solutions occurs in the DAE system (1).

\section{Geometry of transient stabilization via dc link}

Section V discussed the effect of dc current control via the BL system (12). The phase portraits in Section V offer a dynamical viewpoint about the transient stabilization of ac power systems via dc link. Fig. 8 implies that the effect of dc current control appears in phase portraits of the BL system (12). Assigning the phase portraits is therefore a key to regulating transient behavior of the ac power system. Here, if the ac power system and the dc link do not interact, in other words, $K_{V}=K_{I}=0$, then the BL system for the ac power system becomes a gradient system with a potential function $U_{\mathrm{ac}}\left(\theta_{\mathrm{r}}, V_{\mathrm{r}}\right)$. The system is operationally derived by putting $K_{V}=K_{I}=0$ and $X_{\mathrm{c}}=0$ in the BL system (12). The installation of dc link into ac power system is therefore regarded as a perturbation of the gradient BL system. Namely, the transient stabilization via dc link can be investigated using the gradient controlled BL system with input as installation of dc link. This provides a dynamical viewpoint about the transient stabilization.

Note that transient stabilization via dc links is reported in [10]-[13] and is adopted in practical power systems [1], [2]. Unfortunately, the mechanism of stabilization has been not analytically clarified. Fig. 8 also implies that transient behavior of the ac power system is regulated by changing the set-point value $I_{\mathrm{dc}(\mathrm{ref})}$ of dc current. The set-point value $I_{\mathrm{dc}(\mathrm{ref})}$ is one control parameter that is included in the algebraic equations. Hence it is said that the transient stabilization is the regulation of the constraint set, which is a set of variables satisfying algebraic equations, in the DAE system (1). Fig. 8 describes one aspect of regulating the constraint set through the $\mathrm{BL}$ formulation.

\section{Comments to general ac/dc power systems}

Last of all, generalization of the obtained results on a practical ac/dc power system is discussed for two different points. The first point is for general ac/dc power systems containing many synchronous machines and dc links. The general systems show the similar discontinuous dynamics, because their dynamics is analyzed by general DAE systems [16]-[19]. The discontinuity of solutions provides the same analytical viewpoint about transient stabilization via dc links as the ac/dc power system in Fig. 1. The second point is whether the analytical viewpoint based on the simplified model is valid if detailed models of dc controllers are considered such as firing angle controls and VDCOL scheme. An integrated model of transient dynamics is then required to investigate this point. The integrated model is represented by a hybrid dynamical system, because it contains both continuous dynamics of generator/transmissions and discrete events of firing control. Understanding the connection of simplified and hybrid models is therefore central to solving the second point. This is our forthcoming work which is also mentioned in Section VII.

\section{CONCLUSION}

This paper studied discontinuous transient dynamics of an electric power system with dc transmission. The analysis was numerically and analytically performed based on a DAE system. Several discontinuous solutions were numerically presented for concrete fault conditions and were analytically validated using singular perturbation. These results exhibit an example of discontinuous solutions of the DAE system (1) and imply that they can be handled numerically and analytically. Transient stability analysis based on discontinuous solutions was also performed. Through the analysis, we show that transient stabilization via dc transmission is characterized by a dynamical system on constraint set or manifold controlled by input as installation of de transmission.

Many research subjects follow the present study on discontinuous dynamics of the ac/dc power system. As mentioned in Section III, the DAE-based model has great importance for stability analysis of power systems. An energy function method for DAE-based power system models has been developed in [8], [9], [27], [34]. A controlling UEP method with considering the discontinuous solutions is particularly proposed in [27]. This paper provides some characteristics of discontinuous solutions for the DAE system (1). Applying the proposed method in [27] to the ac/dc power system is therefore a next work. The application depends on how an energy function is constructed for the DAE system (1).

Transient discontinuous dynamics is analyzed from a viewpoint of hybrid systems. Hybrid systems are interacting dynamical systems of continuous and discrete-valued variables. Analysis and control of hybrid systems have recently attracted a lot of interest of many researchers: see e.g. [43]. Again note that discontinuous solutions in the DAE system (1) occur when network structure of the ac/dc power system changes due to fault occurrence and clearing. The topology change is modeled as a transition of discrete-valued variables in hybrid systems: see [44] for modeling hybrid voltage dynamics in a 
power system. Hybrid system-based models can also combine the simplified model and detailed one of dc controllers such as firing angle controls and VDCOL scheme. Analysis of discontinuous solutions based on hybrid systems theory is of great importance for not only validating the obtained results in real situation of ac/dc power systems but also exploring stability problems of complex power networks.

\section{ACKNOWLEDGMENT}

Two of the authors (YS and TH) greatly appreciate the fruitful discussion with Professor Philip Holmes at Princeton University and Professor Tsuyoshi Funaki at Kyoto University. The authors are also grateful to anonymous reviewers for their valuable and critical comments.

\section{APPENDIX: DERIVATION OF BOUNDARY LAYER SYSTEM}

This appendix derives the two-dimensional BL system (12). To do this, a reduced DAE system is first induced. From the last equation of (6) and trigonometric functions, the following equalities are derived:

$$
\left\{\begin{array}{l}
K_{I} \mathrm{e}^{V_{\mathrm{r}}} I_{\mathrm{dc}} \cos \varphi_{\mathrm{r}}=\left(K_{V} \mathrm{e}^{V_{\mathrm{r}}} \cos \alpha-\frac{3}{\pi} X_{\mathrm{c}} I_{\mathrm{dc}}\right) I_{\mathrm{dc}}, \\
K_{I} I_{\mathrm{dc}} \mathrm{e}^{V_{\mathrm{r}}} \sin \varphi_{\mathrm{r}}=\sqrt{K_{I}^{2} \mathrm{e}^{2 V_{\mathrm{r}}}-\left(K_{I} \mathrm{e}^{V_{\mathrm{r}}} \cos \varphi_{\mathrm{r}}\right)^{2}} \cdot I_{\mathrm{dc}},
\end{array}\right.
$$

where it is here assumed that $I_{\mathrm{dc}} \neq 0, \sin \varphi_{\mathrm{r}}>0$, and $K_{I}>0$ in the DAE system (6). This is relevant to considering the transient stability of the practical ac/dc power system. Substituting (13) to (6) makes it possible to eliminate the variable $\varphi_{\mathrm{r}}$ from the DAE system (6). Thus, the following reduced DAE system is derived:

$$
\left\{\begin{aligned}
& \frac{T_{d 0}^{\prime}}{L_{d}-L_{d}^{\prime}} \frac{\mathrm{d} v_{q}^{\prime}}{\mathrm{d} t}=-\frac{\partial \mathcal{U}_{\mathrm{ac}}}{\partial v_{q}^{\prime}}, \\
& \frac{\mathrm{d} \delta}{\mathrm{d} t}=\omega \\
& 2 H \frac{\mathrm{d} \omega}{\mathrm{d} t}=-D \omega-\frac{\partial \mathcal{U}_{\mathrm{ac}}}{\partial \delta} \\
& L_{\mathrm{dc}} \frac{\mathrm{d} I_{\mathrm{dc}}}{\mathrm{d} t}=-\frac{\partial \mathcal{U}_{\mathrm{dc}}}{\partial I_{\mathrm{dc}}}+K_{V}\left(\mathrm{e}^{V_{\mathrm{r}}} \cos \alpha-V_{\mathrm{i}} \cos \gamma\right), \\
& 0=-\frac{\partial \mathcal{U}_{\mathrm{ac}}}{\partial \theta_{\mathrm{r}}}-\left(K_{V} \mathrm{e}^{V_{\mathrm{r}}} \cos \alpha-\frac{3}{\pi} X_{\mathrm{c}} I_{\mathrm{dc}}\right) I_{\mathrm{dc}} \\
& 0-\frac{\partial \mathcal{U}_{\mathrm{ac}}}{\partial V_{\mathrm{r}}} \\
&-\sqrt{K_{I}^{2} \mathrm{e}^{2 V_{\mathrm{r}}}-\left(K_{V} \mathrm{e}^{V_{\mathrm{r}}} \cos \alpha-\frac{3}{\pi} X_{\mathrm{c}} I_{\mathrm{dc}}\right)^{2}} \cdot I_{\mathrm{dc}}
\end{aligned}\right.
$$

where $\boldsymbol{x}=\left(v_{q}^{\prime}, \delta, \omega, I_{\mathrm{dc}}\right)^{\mathrm{T}} \in X=\mathbb{R} \times \mathbb{S}^{1} \times \mathbb{R} \times(\mathbb{R} \backslash$ $\left.\left\{I_{\mathrm{dc}} \mid I_{\mathrm{dc}}=0\right\}\right), \boldsymbol{y}=\left(\theta_{\mathrm{r}}, V_{\mathrm{r}}\right)^{\mathrm{T}} \in Y=\mathbb{S}^{1} \times \mathbb{R}$. It should be noted that dynamics of the reduced DAE system (14) is identical to that of the DAE system (6) under the conditions $I_{\mathrm{dc}} \neq 0, \sin \varphi_{\mathrm{r}}>0$, and $K_{I}>0$. In addition, by introducing a small positive parameter $\varepsilon$, the corresponding SP system is derived:

$$
\left\{\begin{aligned}
\frac{T_{d 0}^{\prime}}{L_{d}-L_{d}^{\prime}} \frac{\mathrm{d} v_{q}^{\prime}}{\mathrm{d} t} & =-\frac{\partial \mathcal{U}_{\mathrm{ac}}}{\partial v_{q}^{\prime}}, \\
\frac{\mathrm{d} \delta}{\mathrm{d} t} & =\omega \\
2 H \frac{\mathrm{d} \omega}{\mathrm{d} t} & =-D \omega-\frac{\partial \mathcal{U}_{\mathrm{ac}}}{\partial \delta} \\
L_{\mathrm{dc}} \frac{\mathrm{d} I_{\mathrm{dc}}}{\mathrm{d} t} & =-\frac{\partial \mathcal{U}_{\mathrm{ac}}}{\partial I_{\mathrm{dc}}}+K_{V}\left(\mathrm{e}^{V_{\mathrm{r}}} \cos \alpha-V_{\mathrm{i}} \cos \gamma\right), \\
\varepsilon \frac{\mathrm{d} \theta_{\mathrm{r}}}{\mathrm{d} t} & =-\frac{\partial \mathcal{U}_{\mathrm{ac}}}{\partial \theta_{\mathrm{r}}}-\left(K_{V} \mathrm{e}^{V_{\mathrm{r}}} \cos \alpha-\frac{3}{\pi} X_{\mathrm{c}} I_{\mathrm{dc}}\right) I_{\mathrm{dc}} \\
\varepsilon \frac{\mathrm{d} V_{\mathrm{r}}}{\mathrm{d} t} & =-\frac{\partial \mathcal{U}_{\mathrm{ac}}}{\partial V_{\mathrm{r}}} \\
- & \sqrt{K_{I}^{2} \mathrm{e}^{2 V_{\mathrm{r}}}-\left(K_{V} \mathrm{e}^{V_{\mathrm{r}}} \cos \alpha-\frac{3}{\pi} X_{\mathrm{c}} I_{\mathrm{dc}}\right)^{2}} \cdot I_{\mathrm{dc}} .
\end{aligned}\right.
$$

Applying the variable transformation $1 / s=\varepsilon / t$ to the SP system (15) and freezing $\varepsilon=0$ induce the two-dimensional BL system (12).

\section{REFERENCES}

[1] K. R. Padiyar, HVDC Power Transmission Systems: Technology and System Interactions. New Delhi: Wiley Eastern, 1990.

[2] T. Machida, Ed., DC Transmission Engineering. Tokyo: Tokyo Denki University Press, 1999, (in Japanese).

[3] T. J. Hammons, D. Woodford, J. Loughtan, M. Chamia, J. Donahoe, D. Povh, B. Bisewski, and W. Long, "Role of hvdc transmission in future energy development," IEEE Power Energy Mag., vol. 20, no. 2, pp. 10-15, February 2000.

[4] D. Povh, "Use of HVDC and FACTS," Proc. IEEE, vol. 88, no. 2, pp. 235-245, February 2000.

[5] B. Anderson and C. Barker, "A new era in HVDC?" IEE Review, vol. 46, no. 2, pp. 33-39, March 2000

[6] Y. Sekine, S. Kato, T. Motoki, and S. Ito, "Kii Channel HVDC Link between Shikoku and Kansai Electric Power Companies by submarine cables," in Proc. CIGRÉ Tokyo Symposium, 1995, paper \#220-04.

[7] E. W. Kimbark, Power System Stability. New York: John Wiley \& Sons, 1947, vol. I.

[8] H. D. Chiang, "Power system stability," in Wiley Encyclopedia of Electrical and Electronics Engineering, J. G. Webster, Ed. New York: John Wiley \& Sons, March 1999, pp. 105-137.

[9] C. C. Chu, "Transient dynamics of electric power systems: Direct stability assessment and chaotic motions," PhD Dissertation, Cornell University, January 1996.

[10] T. Machida, "Improving transient stability of ac system by joint usage of dc system," IEEE Trans. Power App. Syst., vol. PAS-85, no. 3, pp. 226-232, March 1966.

[11] P. K. Dash, B. Puthal, O. P. Malik, and G. S. Hope, "Transient stability and optimal control of parallel a.c.-d.c. power systems," IEEE Trans. Power App. Syst., vol. PAS-95, no. 3, pp. 811-820, May/June 1976.

[12] N. A. Vovos and G. D. Galanos, "Transient stability of ac-dc systems," IEEE Trans. Power App. Syst., vol. PAS-98, no. 4, pp. 1375-1383, July/August 1979.

[13] — , "Enhancement of the transient stability of integrated ac/dc systems using active and reactive power modulation," IEEE Trans. Power App. Syst., vol. PAS-104, no. 7, pp. 1696-1702, July 1985.

[14] H. A. Peterson, D. K. Reitan, and A. G. Phadke, "Parallel operation of ac and de power transmission," IEEE Trans. Power App. Syst., vol. PAS-84, no. 1, pp. 15-19, January 1965.

[15] H. A. Peterson, J. P. C. Krause, J. F. Luini, and C. H. Thomas, "An analog computer study of a parallel ac and dc power system," IEEE Trans. Power App. Syst., vol. PAS-85, no. 3, pp. 191-209, March 1966.

[16] M. A. Pai, K. R. Padiyar, and C. Radhakrishna, "Transient stability analysis of multi-machine ac/dc power systems via energy-function method," IEEE Trans. Power App. Syst., vol. PAS-100, no. 12, pp. 50275035, December 1981. 
[17] Y. X. Ni and A. A. Fouad, "A simplified two-terminal hvde model and its use in direct transient stability assessment," IEEE Trans. Power Syst., vol. PWRS-2, no. 4, pp. 1006-1012, November 1987.

[18] C. L. DeMarco and C. A. Cañizares, "A vector energy function approach for security analysis of ac/dc systems," IEEE Trans. Power Syst., vol. 7, no. 3, pp. 1001-1011, August 1992.

[19] K. R. Padiyar and H. S. Y. Sastry, "A structure-preserving energy function for stability analysis of ac/dc systems," Sädhanā: Academy Proceedings in Engineering Science, vol. 18, no. 5, pp. 787-799, September 1993.

[20] Y. Susuki and T. Hikihara, "Transient dynamics of electric power system with dc transmission: Fractal growth in stability boundary," IEE Proc.Circ. Dev. Syst., vol. 152, no. 2, pp. 159-164, April 2005.

[21] _ "Stability region in electric power system with dc transmission based on differential-algebraic equation," in Proc. 37th International Universities Power Engineering Conference, vol. 2, Stafford, United Kingdom, September 9-11 2002, pp. 745-749.

[22] _ _An analysis with differential-algebraic equation in electric power system with dc transmission," in Proc. IEEE/PES Transmission and Distribution Conference and Exhibition 2002: Asia Pacific, Yokohama, Japan, October 6-10 2002, pp. 1933-1936.

[23] Y. Susuki, T. Hikihara, and H. D. Chiang, "Stability boundaries analysis of electric power system with dc transmission based on differentialalgebraic equation system," IEICE Trans. Fund. Electr., vol. E87-A, no. 9, pp. 2339-2346, September 2004.

[24] _ " "Transient stability and discontinuous solution in electric power system with dc transmission: A study with DAE system," in Proc. 2004 International Symposium on Nonlinear Theory and its Applications, Fukuoka, Japan, November 29-December 3 2004, pp. 423-426, (This paper contains some numerical mistakes.)

[25] A. R. Bergen and D. J. Hill, "A structure preserving model for power system stability analysis," IEEE Trans. Power App. Syst., vol. PAS-100, no. 1, pp. 25-35, January 1981.

[26] S. Sastry and P. Varaiya, "Hierarchical stability and alert steering control of interconnected power systems," IEEE Trans. Circuits Syst., vol. CAS27, no. 11, pp. 1102-1112, November 1980.

[27] Y. Zou, M. H. Yin, and H. D. Chiang, "Theoretical foundation of the controlling UEP method for direct transient-stability analysis of network-preserving power system models," IEEE Trans. Circuits Syst. $I$, vol. 50, no. 10 , pp. 1324-1336, Octorber 2003.

[28] N. A. Tsolas, A. Arapostathis, and P. P. Varaiya, "A structure preserving energy function for power system transient stability analysis," IEEE Trans. Circuits Syst., vol. CAS-32, no. 10, pp. 1041-1049, October 1985.

[29] Y. Tamura, H. Mori, and S. Iwamoto, "Relationship between voltage instability and multiple load flow solutions in electric power systems," IEEE Trans. Power App. Syst., vol. PAS-102, no. 5, pp. 1115-1123, May 1983.

[30] C. L. DeMarco and A. R. Bergen, "Application of singular perturbation techniques to power system transient stability analysis," in Proc. International Symposium on Circuits and Systems, 1984, pp. 597-601.

[31] H. G. Kwatny, A. K. Pasrija, and L. Y. Bahar, "Static bifurcations in electric power networks: Loss of steady-state stability and voltage collapse," IEEE Trans. Circuits Syst., vol. CAS-33, no. 10, pp. 981991, Octorber 1986.

[32] I. A. Hiskens and D. J. Hill, "Energy functions, transient stability and voltage behavior in power systems with nonlinear loads," IEEE Trans. Power Syst., vol. 4, no. 4, pp. 1525-1533, October 1989.

[33] D. J. Hill and I. M. Y. Mareels, "Stability theory for differential/algebraic systems with application to power systems," IEEE Trans. Circuits Syst., vol. 37, no. 11, pp. 1416-1423, November 1990.

[34] H. D. Chiang and L. Fekih-Ahmed, "On the direct method for transien stability analysis of power system structure preserving models," in Proc. International Symposium on Circuits and Systems, 1992, pp. 2545-2548.

[35] V. Venkatasubramanian, H. Schättler, and J. Zaborszky, "Voltage dynamics: Study of a generator with voltage control, transmission, and matched MW load," IEEE Trans. Autom. Control, vol. 37, no. 11, pp. 1717-1733, November 1992.

[36] C. A. Cañizares, F. L. Alvarado, C. L. DeMarco, I. Dobson, and W. F. Long, "Point of collapse methods applied to ac/dc power systems," IEEE Trans. Power Syst., vol. 7, no. 2, pp. 673-683, May 1992.

[37] F. Takens, "Constrained equations; A study of implicit differential equations and their discontinuous solutions," in Structural Stability, the Theory of Catastrophes, and Applications in the Sciences, ser. Lecture Notes in Mathematics. Springer-Verlag, 1976, vol. 525, pp. 143-234.

[38] S. S. Sastry and C. A. Desoer, "Jump behavior of circuits and systems," IEEE Trans. Circuits Syst., vol. CAS-28, no. 12, pp. 1109-1124, December 1981.
[39] E. Hairer and G. Wanner, Solving Ordinary Differential Equations 2. Stiff and Differential-Algebraic Problems, 2nd ed., ser. Springer Series in Computational Mathematics. Berlin Heidelberg: Springer-Verlag, 1996, vol. 14

[40] V. Venkatasubramanian, H. Schättler, and J. Zaborszky, "Dynamics of large constrained nonlinear systems-A taxonomy theory," Proc. IEEE, vol. 83, no. 11, pp. 1530-1561, November 1995.

[41] H. K. Khalil, Nonlinear Systems, 3rd ed. New Jersey: Prentice Hall, 2002.

[42] Y. Susuki, "Transient dynamics and stability boundaries in electric power system with dc transmission," PhD Dissertation, Kyoto University, November 2004.

[43] M. Domenica, D. Benedetto, and A. Sangiovanni-Vincentelli, Eds., Hybrid Systems: Computation and Control, ser. Lecture Notes in Computer Science 2034. Springer-Verlag, 2001

[44] Y. Susuki and T. Hikihara, "Predicting voltage instability of power system via hybrid system reachability analysis," in Proc. 2007 American Control Conference, New York City, United States, July 11-13 2007, (accepted).

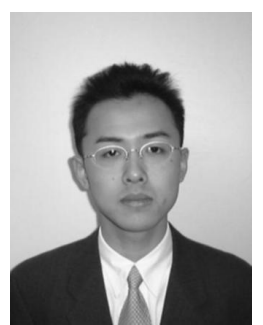

Yoshihiko Susuki was born in Japan on December 31, 1977. He received his bachelor, master, and $\mathrm{PhD}$ degrees from Kyoto University in 2000, 2002, and 2005, respectively. In 2005 he joined the Department of Electrical Engineering at Kyoto University, where he is an Assistant Professor. In 2003 he was a visiting scholar in the School of Electrical Engineering at Cornell University. His research interests include nonlinear dynamics, power system engineering, and control applications. He is a member of IEEJ, IEICE, and ISCIE

Takashi Hikihara received Ph.D. degree from Kyoto University in 1990. In 1987 he joined the faculty of Department of Electrical Engineering, Kansai University. From 1993 to 1994, he was a visiting researcher at Cornell University. Since 1997 he has been with the Department of Electrical Engineering at Kyoto University, where he is currently a Professor. His research interests are including nonlinear science, analysis of nonlinear system, applications and control of nonlinear dynamics, nano-mechanical systems, and power engineering. He is currently an associate editor of Journal of Circuits, Systems, and Computers. He also served as an editor of the several special issues of Transactions of IEICE, Japan, IEE, Japan. He is a regular member of the IEEE, IEE, APS, SIAM, SICE, ISICE and IEE, Japan.

Hsiao-Dong Chiang received his $\mathrm{Ph}$. D. degree from University of California, Berkeley in 1986. After receiving the Ph.D. degree in electrical engineering and computer science, he worked on a special project at the Pacific Gas and Electricity Company. In 1987, he joined the faculty of the School of Electrical Engineering at Cornell University. In 1988 the National Science Foundation named Chiang as a recipient of an Engineering Research Initiation Award. In 1989, he received a Presidential Young Investigator Award from the National Science Foundation. In 1990 he was selected by a Merrill Presidential Scholar as the faculty member who had the most positive effect on that student's education at Cornell. He was an associate editor of IEEE Transactions on Circuits and Systems 1990-91 and was also an editor for express letters of IEEE Transactions on Circuits and Systems I: Fundamental Theory and Applications. He holds five U.S. patents and several consultant positions. $\mathrm{He}$ is a IEEE Fellow. His research interests include (1) nonlinear systems theory, computation, and application to electrical circuits, signals and systems; (2) power system stability and control, security assessments and enhancements; (3) distribution system analysis, control and design; (4) intelligent information processing system; (5) drawing digitization and automated mapping/facility management; and (6) global optimization techniques and applications. 